\title{
Arte y Ciudad en la Educación Infantil Keith Haring
}

\author{
Marcos Chica Díaz ${ }^{1}$
}

\begin{abstract}
Resumen
La experiencia realizada sintetiza una secuencia didáctica de expresión artística en la escuela. El proceso se ha llevado a cabo en un centro público de educación infantil y primaria en el municipio de San Sebastián de los Reyes, concretamente con el segundo nivel de infantil. Desde el trabajo del autor Keith Haring, presentamos contenidos curriculares referentes a los lenguajes, tanto los verbales, plásticos y corporales, como aquellos relacionados con la aproximación a los lenguajes escritos. Al mismo tiempo, referirse a la obra iconográfica de Haring, nos permite una reciprocidad ciudad-escuela-arte. Así, esta práctica nos abre un expectante planteamiento curricular didáctico, siempre guiado por aprendizajes creativos en dos formas. Investigación y dirección. Las producciones plasmadas en los muros del centro escolar, mantienen la atención de los viandantes de la propia ciudad. Por tanto, redefinir las líneas pedagógicas en los proyectos educativos es el primer paso a seguir, sin dejar de lado la ciudad y los ciudadanos, así como la creatividad de los propios alumnos.
\end{abstract}

Palabras-clave: Pensamiento creativo. Currículo. Iconografía. Ciudad. Línea.

\section{ART AND CITY IN EARLY CHILDHOOD EDUCATION. KEITH HARING}

\begin{abstract}
The experience made synthesizes a sequence didactic artistic expression at school. The process was conducted in a public school of infantile and primary education in the municipality of San Sebastián de los Reyes, particularly with the second level of child. From the author's work Keith Haring, present curriculum regarding languages, both verbal and body plastic, such as those related to the approach to written languages. At the same time, referring to the iconographic work of Haring, allows a city-school-art reciprocity. Thus, this practice opens an expectant curricular teaching approach, always guided by creative learning in two ways. Research and direction. Productions reflected on the walls of the school, maintain the attention of passersby in the city itself. Therefore redefine the pedagogical lines in educational projects is the first step to follow, without leaving the city and citizens, as well as the creativity of the students.
\end{abstract}

Keywords: Creative thinking. Curriculum. Iconography. City. Line.

1 Departamento de Didácticas Específicas. Ciencias sociales. Maestro especialista en Educación Infantil. Comunidad de Madrid. marcoschicadiaz@gmail.com 
La capacidad de expresarnos libremente facilita una ordenación de las ideas en nuestras mentes. Desde nuestra intervención didáctica, se ha cualificado constantemente, la posibilidad de expresar el pensamiento creativo del alumno de una manera gráfica e individualizada, de modo que, los diferentes materiales utilizados, tanto los artísticos plásticos, como los soportes y escenarios ofertados (papeles en blanco de distintos tamaños, murales, folios, materiales reciclados, y diferentes espacios del centro, como paredes, pasillos o las aulas no habituales), han justificado nuestra mediación didáctica.

Consiguientemente, la importancia de estudiar un autor relevante como Haring, surge por azar del propio grupo. Estas casualidades, son fruto de la observación diaria hacia los alumnos que forman el grupo de 4 años, reorientando así la programación didáctica dentro de la mejora educativa del aula.

Al investigar en la biografía de Keith Haring, repercutimos en varias cuestiones importantes (CASAS, 2013): La simplicidad artística y la importancia del arte público. Esta expresión gráfica distintiva de Keith, basada en el predominio de la línea, sobresale en la composición directa con colores vibrantes y saturados. Reinterpretar algunas ideas de Haring es el objetivo primordial que nos formulamos en esta secuencia innovadora, además de, conocer la repercusión social tanto de su iconografía, como de su obra pública. Haring llegó a experimentar la performance, el vídeo, la instalación y el collage, elementos que se pueden desentrañar didácticamente en cualquier contexto educativo. En un momento dado de su vida, encuentra un medio muy fuerte que le permitirá comunicarse con el público, como los paneles publicitarios de metro en las estaciones de Nueva York, creando así, una serie de dibujos muy significativos socialmente, realizados a tiza de color blanca sobre paneles de fondos oscuros.

Por lo tanto, la conjugación artística y la capacidad creadora en estas edades (LOWEMFELD; BRITAIN, 1972), permiten crear una simplicidad atractiva y significativa para este nivel educativo dentro del marco curricular; es decir, significativa en la relación que puedan tener las producciones de los propios alumnos en consecuencia con el momento evolutivo que se encuentre, $y$, 
significativas en el desarrollo del dibujo en cuanto al conocimiento del esquema corporal. Corroborando así los estudios de las etapas del grafismo (LOWENFELD; BRITAIN, 1972).

Cabe resaltar, la asistencia proporcionada por el equipo directivo, compañeros del centro, y, en especial una compañera en prácticas del grado de infantil de la UAM, ${ }^{2}$ en la ejecución de la propuesta.

\section{Antecedentes}

El grupo se encuentra en un momento evolutivo pre-esquemático (LOWEMFELD; BRITAIN, 1972). En los dibujos que realizan los niños a estas edades y en la idea que desarrollan de la composición del esquema corporal, tienden a cerrar las diferentes partes del cuerpo; la cabeza, las manos, los brazos, el tronco y los pies. Estos símbolos son totalmente distintos a lo que plantea Haring en la composición de las figuras lineales, por lo que, la ejecución en la reinterpretación puede ser dificultosa.

No obstante, como se trata de potenciar la creatividad (BORTHWICK, 1982) y además se ha trabajado mucho dibujo y grafismo durante los dos cursos escolares anteriores, el resultado puede ser bastante auténtico, al igual que en ocasiones anteriores generadas con el mismo grupo (CHICA DÍAZ et al., 2014).

De cualquier modo, la creatividad y los lenguajes artísticos son contenidos propiamente del currículo infantil (Decreto17/2008), y que, de manera globalizada juegan un papel muy importante en la adquisición de múltiples capacidades. Indistintamente la actual ley educativa LOMCE ("Ley Orgánica 8/2013, de 9 de diciembre, para la mejora de la calidad educativa, LOMCE", 2013), no hace referencia a la etapa de la Educación Infantil, pero si modifica algunos principios educativos para todas las etapas, que como tales, afectan a ésta, en las modificaciones que realizan al artículo $1^{\circ}$ de la LOE. Por otro lado,

${ }^{2}$ C. Guindeo Aguerrí ha sido la estudiante colaboradora durante 5 meses en el centro, realizando sus prácticas de grado de maestra. 
en una disposición final, la LOMCE, señala que el Gobierno establecerá las bases de la educación plurilingüe desde segundo ciclo de Educación Infantil hasta Bachillerato, previa consulta a las Comunidades Autónomas.

Centrándonos en un teórico actual muy célebre en la sociedad presente, Howard Gardner, promueve la potencialización de la creatividad individual en la etapa escolar (1988). El individuo creativo es aquel que puede resolver cualquier situación; debemos dejar que el pensamiento divergente aflore en las aulas de manera libre, ofreciendo una pluralidad de herramientas en cuanto a la actuación en diferentes áreas o materias. Gardner defiende que las primeras experiencias de los niños con el arte y su relación con la creatividad, se forjan desde la escuela (1997), sobre todo, en la etapa infantil.

El pensamiento del niño es sincrético, egocéntrico e irreversible (PIAGET, 1973), pero a su vez, genera un proceso de cognición conceptual de asimilación y de acomodación de su propio mundo simbólico, en donde pretende exponer por sí mismo- si se le permite desde la vigilancia del adulto- sus ideas. Sin embargo, la presión a la que están sometidos en cuanto a la adquisición de contenidos (GARDNER, 1997) y el inquietante murmullo social el qué dirán, o el miedo a qué sobre estas propias concepciones creativas, pueden ser controvertidas por el adulto (bien por el maestro magistral o adulto social), vulnerando así la capacidad creativa e individual de los alumnos a medida que avanza su etapa escolar. En definitiva, los procesos curriculares tienen que ser enseñados adecuadamente y no la idea, ya que, ésta aparece como personal e intrínsecamente social.

También Vygotsky (VYGOTSKY, 1955), habla de la creatividad refiriéndose a ella como: “...Toda realización humana creadora de algo nuevo, ya se trate de reflejos de algún objeto del mundo exterior, ya de determinadas construcciones del cerebro o del sentimiento que vive y se manifiesta sólo en el propio ser humano”. El entorno escolar es el primer contexto social de relación junto al de la familia, y supone por ello, un espacio nuevo de interrelación y aprendizaje separado al mismo tiempo del entorno familiar. La idea actual de la escuela está cambiando (COLL, 2001), ya que procura un crecimiento personal como individuo, independientemente de su condición o carácter social. 
Por otro lado, las ciudades actuales se ofrecen como ciudades que educan. Bien, esta casuística concuerda con el sentido de la escuela. Hay una necesidad mutua de aprender a ser ciudadanos activos y comprometidos socialmente con el desarrollo sostenible (GALLENO, 2001) y el avance de la propia sociedad. La escuela dentro de la ciudad conduce a estos fines. El mismo Pablo Freire, aportó una idea notable donde citamos su importancia, al igual que se ha aludido en otros congresos importantes sobre la importancia de la ciudad (RODRIGUEZ BELTRÁN, 2012) "[...] la idea de ciudad educadora a partir de la necesidad de educar, de aprender, de imaginar siendo educadora, la ciudad es a su vez educada [...]".

\section{Proceso de la intervención Didáctica:}

Los currículos oficiales identifican los principios didácticos de orientación constructivista, como la síntesis integradora de un conjunto de teorías (VIELMA; SALAS, 2000). Estas teorías tienen en común, defender el aprendizaje como el resultado de un proceso de construcción o reconstrucción de la realidad. Por consiguiente, el constructivismo ha sido el eje primordial de nuestra propuesta didáctica, deteniéndonos en momentos puntuales para reconducir lo aprehendido y guiar a los alumnos en el proceso. Con esta intervención destacamos una serie de logros a conseguir como: Conocer parte de la vida del autor y su repercusión social, identificando algunas de sus principales características de su obra. Desarrollar la capacidad artística de los participantes, profundizando en la composición de la figura y el esquema corporal (PULEO ROJAS, 2012) o hacer sentir a los alumnos como una parte importante de su ciudad, inculcando valores de respeto y gusto por lo estético.

Los alumnos que han participado en la propuesta tenían entre 4 y 5 años de edad, en concreto el $2^{\circ}$ nivel de Educación Infantil. En cuanto a los recursos personales han sido el tutor del grupo, 2 maestros de apoyo y los 25 alumnos/ as, por supuesto, toda la comunidad educativa siempre y cuando se requirió su colaboración. Señalar que este grupo realizó otra propuesta de arte similar (CHICA DÍAZ et al., 2014). Por lo tanto, la enseñanza aplicada en la que se centra el trabajo, reafirma un valor añadido en el sentido didáctico. 


\section{Propuestas de Actividades}

Las sesiones se plantearon durante el mes de mayo, en el horario de mañana de 9 a 11:00 horas, enmarcadas dentro de la metodología propia del aula, como son los rincones de actividad (CHICA DÍAZ, 2015). La línea de trabajo, permite al grupo cierta autonomía y responsabilidad a la hora de elaborar propuestas o de resolver otras encomendadas por el tutor.

Tabla 1 - Secuencia de actividades programáticas, (Tablas de diseño propio)

\begin{tabular}{|c|c|c|c|c|c|}
\hline $\begin{array}{l}\text { Sesiones } \\
\text { Fecha }\end{array}$ & Tarea & Partes de la actividad & Tiempos & Materiales & alumnos \\
\hline $\begin{array}{l}\text { Sesión } 1 \\
18-5-2014\end{array}$ & $\begin{array}{l}\text { Conoci- } \\
\text { miento } \\
\text { biográfico } \\
\text { del autor }\end{array}$ & $\begin{array}{l}\text { Observación de dife- } \\
\text { rentes láminas. } \\
\text { Debate. Y Reflexión. } \\
\text { Imitación de posturas } \\
\text { corporales. }\end{array}$ & $\begin{array}{c}1 \text { hora } 30 \\
\text { minutos }\end{array}$ & $\begin{array}{c}\text { Laminas impresas } \\
\text { sobre la obra del } \\
\text { autor. Cuadernillo } \\
\text { biográfico } \\
\text { Pizarra digital }\end{array}$ & 25 \\
\hline $\begin{array}{l}\text { Sesión } 2 \\
20-5-2014\end{array}$ & $\begin{array}{l}\text { Pieza } \\
\text { grupal }\end{array}$ & $\begin{array}{c}\text { Observación de } \\
\text { diferentes láminas y } \\
\text { elección de alguna } \\
\text { para su realización en } \\
\text { la pizarra veleda de } \\
\text { manera individual. }\end{array}$ & $\begin{array}{l}45 \text { minu- } \\
\text { tos }\end{array}$ & $\begin{array}{c}\text { Laminas impresas } \\
\text { sobre la obra del } \\
\text { autor. } \\
\text { Pizarra veleda } \\
\text { Rotuladores veleda }\end{array}$ & 25 \\
\hline $\begin{array}{l}\text { sesión } 3 \\
21-5-2014\end{array}$ & $\begin{array}{l}\text { Pieza indi- } \\
\text { vidual }\end{array}$ & $\begin{array}{c}\text { Representación } \\
\text { individual de la obra } \\
\text { escogida por todos. }\end{array}$ & $\begin{array}{l}30 \text { minu- } \\
\text { tos }\end{array}$ & $\begin{array}{l}\text { Laminas impresas } \\
\text { sobre el autor. } \\
\text { Lapiceros, pinturas } \\
\text { de madera. } \\
\text { Folios de colores }\end{array}$ & 25 \\
\hline $\begin{array}{l}\text { sesión } 4 \\
22-5-2015\end{array}$ & $\begin{array}{l}\text { Compo- } \\
\text { sición de } \\
\text { un Mural } \\
\text { colectivo }\end{array}$ & $\begin{array}{l}\text { Representación grupal } \\
\text { sobre papel continúo. } \\
\text { Silueta y relleno }\end{array}$ & $\begin{array}{l}45 \text { minu- } \\
\text { tos }\end{array}$ & $\begin{array}{l}\text { Laminas impresas } \\
\text { sobre el autor. } \\
\text { Papel continuo } \\
\text { Temperas y pinceles }\end{array}$ & 23 \\
\hline $\begin{array}{l}\text { sesión } 5 \\
25-5-2015\end{array}$ & $\begin{array}{l}\text { Compo- } \\
\text { sición de } \\
\text { un Mural } \\
\text { colectivo }\end{array}$ & $\begin{array}{c}\text { Representación grupal } \\
\text { sobre papel continúo. } \\
\text { Silueta y relleno. } \\
\text { Fondo }\end{array}$ & $\begin{array}{l}45 \text { minu- } \\
\text { tos }\end{array}$ & $\begin{array}{l}\text { Laminas impresas } \\
\text { sobre el autor. } \\
\text { Papel continuo } \\
\text { Temperas y pinceles }\end{array}$ & 25 \\
\hline $\begin{array}{l}\text { sesión } 6 \\
27-5-2015\end{array}$ & $\begin{array}{l}\text { Pintura } \\
\text { sobre el } \\
\text { muro }\end{array}$ & $\begin{array}{l}\text { Representación grupal } \\
\text { sobre el muro. Coloca- } \\
\text { dos por parejas reali- } \\
\text { zan las figuras lineales } \\
\text { de sus compañeros. }\end{array}$ & $\begin{array}{l}45 \text { minu- } \\
\text { tos }\end{array}$ & Lápices de grafito & 24 \\
\hline $\begin{array}{l}\text { sesión } 7 \\
28-5-2015\end{array}$ & $\begin{array}{l}\text { Pintura } \\
\text { sobre el } \\
\text { muro }\end{array}$ & $\begin{array}{l}\text { Pintar la figura reali- } \\
\text { zada por parejas, de un } \\
\text { mismo color escogido } \\
\text { por ellos. }\end{array}$ & $\begin{array}{l}45 \text { minu- } \\
\text { tos }\end{array}$ & $\begin{array}{c}\text { Pintura acrílica } \\
\text { Lápices de grafito } \\
\text { Pinceles y brochas }\end{array}$ & 24 \\
\hline
\end{tabular}




\section{Descripción de las Sesiones}

Sesión 1. 18-5-2015

\section{Conocimiento del autor.}

- Conocimiento biográfico del autor. Obra y vida. Observación de láminas y cuadernillo del autor (Imagen 1 y 2). Planteamos diferentes cuestiones como: ¿Qué veis en esta obra?, ¿Qué aparece en primer plano?, ¿Qué color destaca más?, ¿Qué obra os gusta más?, ¿Qué hacen los personajes?

- Puesta en común.

- Imitación corporal de las posturas que aparecen en las obras observadas.

Imagen 1 y 2 - Observación de láminas impresas de la obra del autor (18-5-2015)
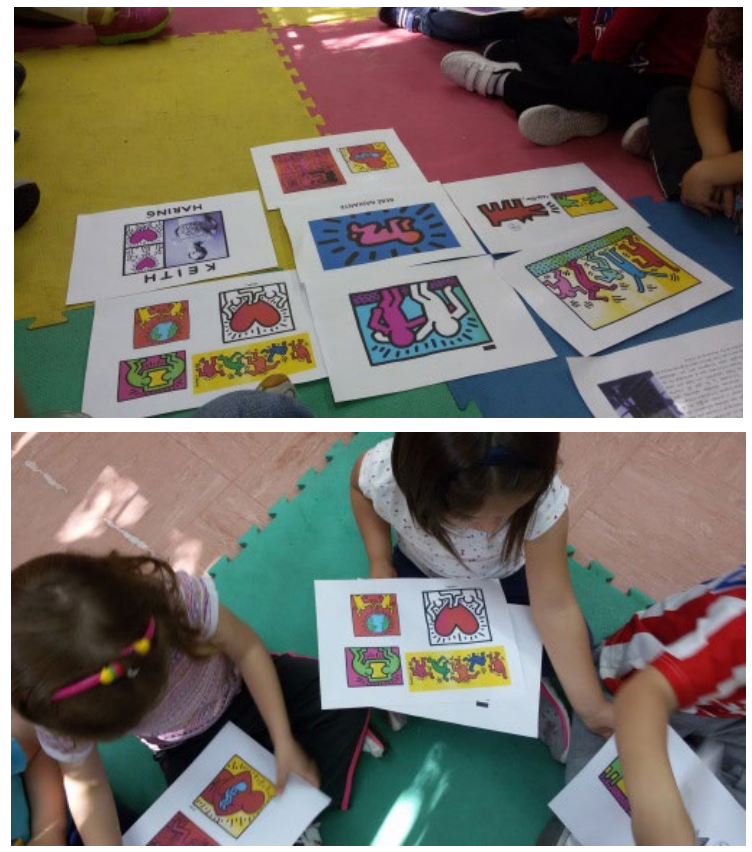

Fuentes obtenidas de https://www.google.es/search?q=imagenes+de+keith+haring\& espv $=2 \&$ biw $=1366 \&$ bih $=589 \&$ source $=1 \mathrm{nms} \& \mathrm{tbm}=\mathrm{isch} \& \mathrm{sa}=\mathrm{X} \& \mathrm{ved}=0 \mathrm{ahUKEwj \textrm {k }} 1 \mathrm{~d}$

TE-tTQAhVC2RoKHWzkDfUQ_AUIBigB\#imgrc=F9KHOac2zhj4xM\%3A 
En cuanto a la ciudad donde vivió el autor, preguntaremos si alguna vez han oído hablar de ella, si saben dónde se ubica. Les mostraremos en la pizarra digital parte de las ciudades en las que desarrolló su vida profesional y en dónde plasmó algunas de sus obras. A continuación realizarán con la ayuda de su propio cuerpo, posturas corporales simulando los diferentes portes que han podido observar en las obras del autor, esta dinámica es muy significativa (COLL, 1988).

Todo este proceso de imitación por parte de los alumnos, se realizaron posteriormente al proceso de observación e indagación de las diferentes obras de Haring. Como las que aparecen en las obras 1 y 2 de Keith Haring. Los planteamientos se han llevado a la práctica desde un enfoque reflexivo y dinamizador, haciendo que las sesiones dedicadas al estudio del autor sean muy significativas para los propios alumnos (MOREIRA; ILEANA, 2003).

Incluso, para los alumnos de la etapa de infantil., hemos ofrecidos juegos interactivos de internet, dónde utilizaban el ratón para colorear figuras preestablecidas del autor (<http://www.haringkids.com/coloringbook/index.html $>$ ).

Imagen 3 y 4 (18-5-2015) - Alumnos imitando diferentes posturas. Bailando, saltando, abrazándose
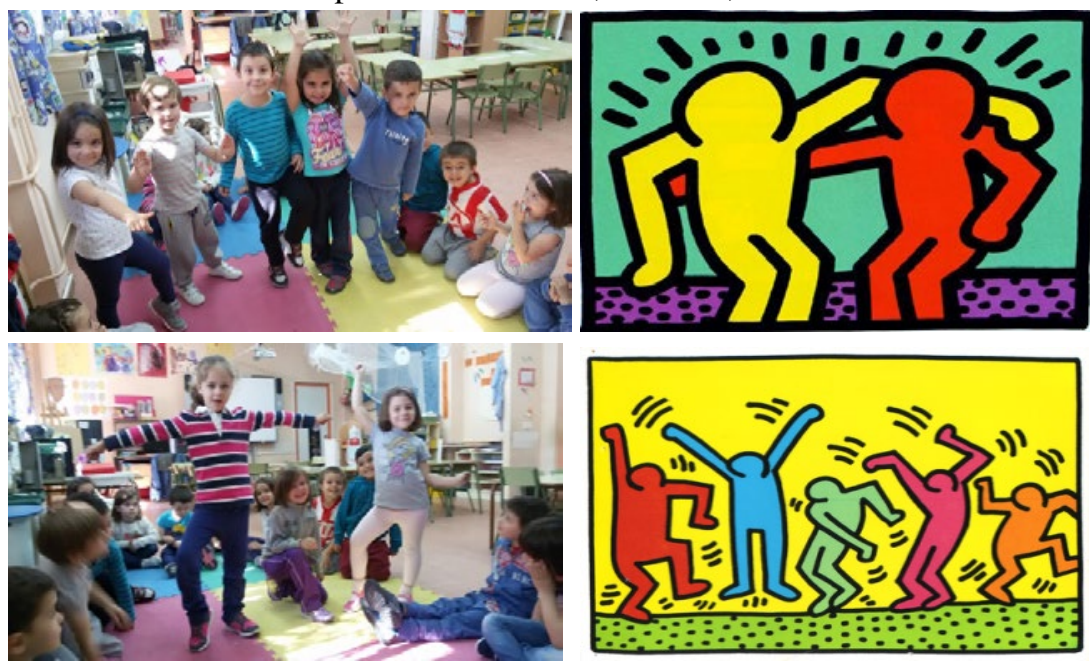

Fuente: Obra $\mathrm{n}^{\circ} 1$ de Haring: Best Buddies, 1990. Nueva York. The Estate of Keith Haring. Disponible en: <http://www.uv.es/cultura/c/docs/expkeithharingcast.htm>. Obra $\mathrm{n}^{\circ} 2$ de Haring: Danza multicolour. 1980. Keith Haring. Disponible en: <http:// www.schulensigriswil.ch/index.php?section=news\&cmd=details1\&newsid=59>. 
Sesión 2. 20-5-2015.

Dibujo de la línea.

Para abordar este tema, explicamos y realizamos previamente unos dibujos lineales a modo de ejemplo en diferentes soportes. Utilizaremos la pizarra veleda como recurso motivador para elaborar nuestros dibujos y, posteriormente los de ellos. Así, fueron acudiendo individualmente para realizar el dibujo de una figura humana, a modo de imitación del propio autor. Intentando no separar la cabeza del tronco.

Imagen 5 - Alumna dibujando figura lineal sobre pizarra veleda (20-5-2015)

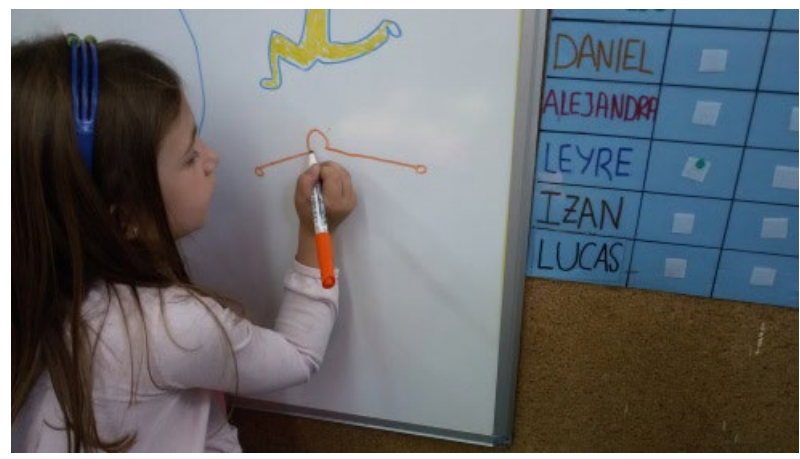


Sesión 3. 21-5-2015.

\section{Pieza individual.}

En esta tercera parte de la propuesta, retomamos el tema a través de un recordatorio breve de los días anteriores. Consecutivamente, les pedimos que realizaran alguna postura corporal y que la recordaran; con esta idea debían plasmar en un folio A2 de color (rojo, azul, rosa, naranja,...), la figura corporal inventada por ellos mismos.

Imagen 6 (21-5-2015) - Ejemplo de una alumna realizando siluetas inventadas

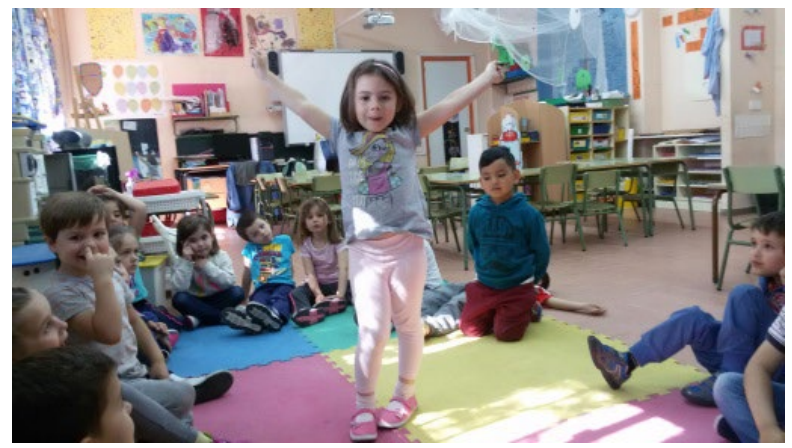

Imagen 7(21-5-2015) - Alumnos realizando las figuras inventadas por ellos.

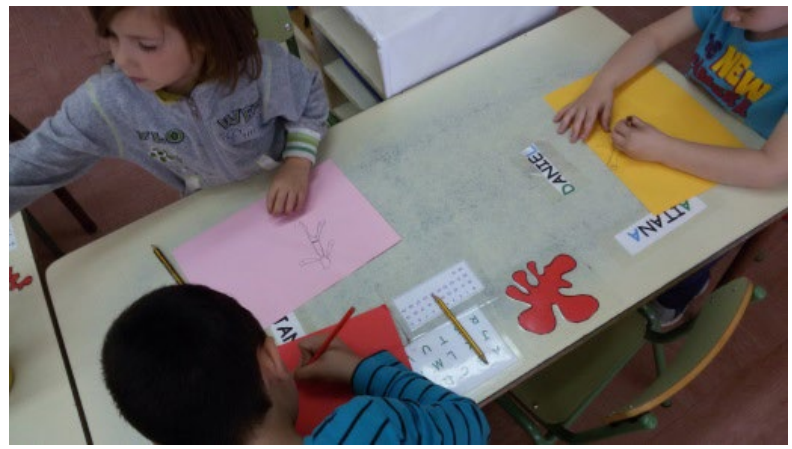


Sesión 4. 22-5-2015.

\section{Composición de mural colectivo}

Esta actividad se efectuó en tres momentos y en dos días distintos.

$1^{\circ}$ momento: los alumnos colocados por parejas dibujaron la silueta del otro respectivamente, sobre un papel continuo de grandes dimensiones.

Imagen 8 y 9 - Ejemplo y resultado de pareja realizando la actividad de plasmar las siluetas. 22-5-2015
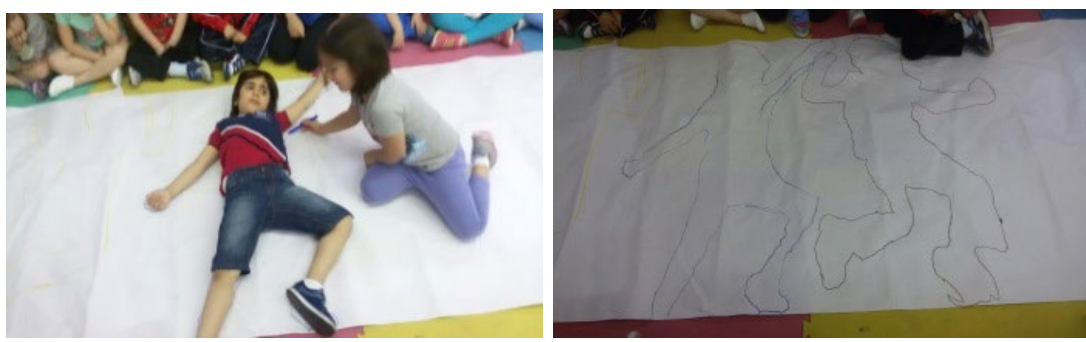

Una vez que realizaron estas siluetas, se abrió un turno de palabra para el debate y la reflexión sobre la propuesta.

$2^{\circ}$ momento: los alumnos colocados en los alrededores de los murales, pintaron el relleno de las siluetas por parejas, realizando cada uno la suya. Podían ayudarse unos a otros, siempre y cuando cumpliera la premisa de pintar la figura de un mismo color. Intentando respetar la línea dibujada, del mismo modo que hacia el autor Haring.

Imagen 10 y 11 - preparación de los materiales para la culminación del mural. 22-5-2015
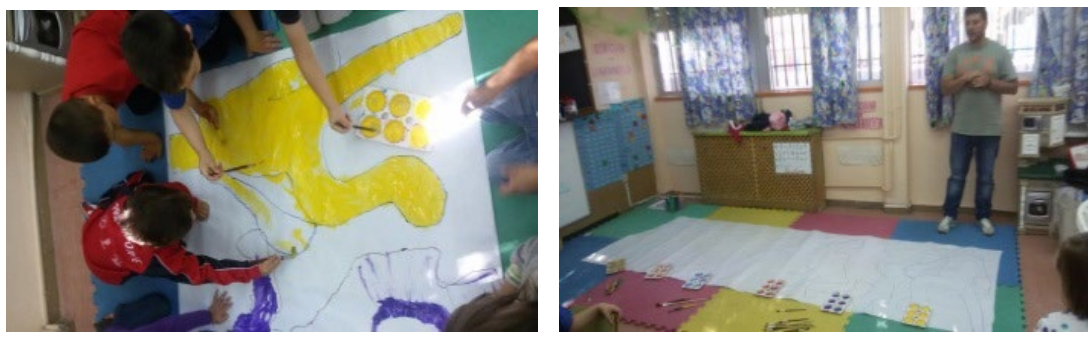
Día 25-5-2015.

$3^{\circ}$ momento: Para matizar el fondo, tuvimos que dejar secar bien las figuras que pintaron los días anteriores. Inicialmente tendrán que repasar la línea de las siluetas. El color escogido es marrón (a criterio nuestro para resaltar las figuras).

\section{Imagen 12 y 13 - resultado de la creación del mural, imitando la obra Danza Multicolor de Haring. 25-5-15}
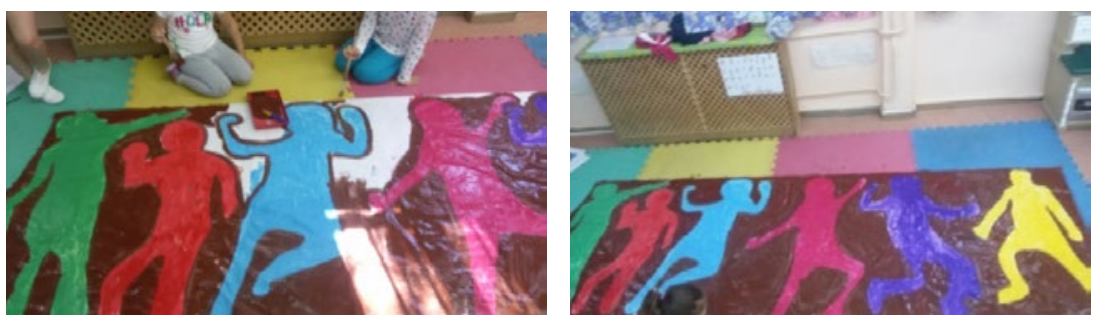

Obra n 3 de Haring “Danza Multicolor 1980”.

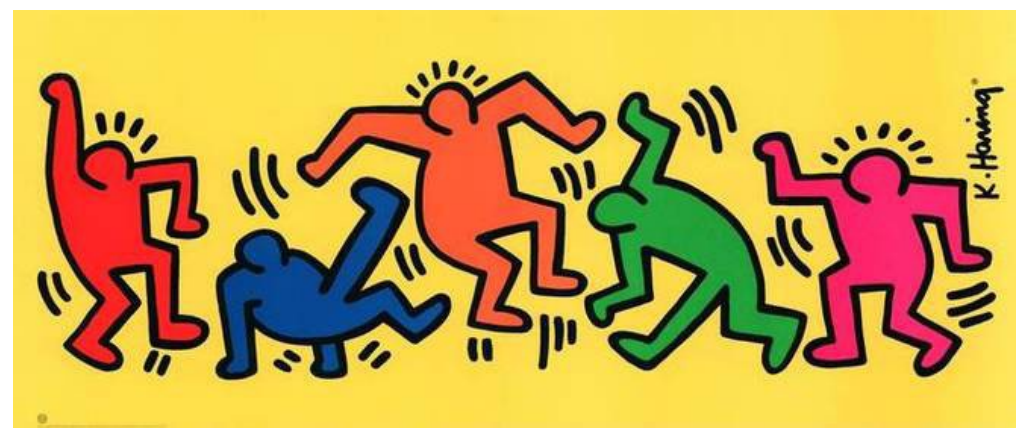

Fuente: <http://www.passion-estampes.com/deco/haringsanstitredansemulticolore5 0x120-es.html>. 
Sesión 6 y 7. 27-5-2015 y día 28-5-2015

Pintura sobre el muro.

En estas dos sesiones imitaremos obras parecidas a las que hizo Haring en lo que se refiere en soportes de grandes dimensiones, paredes o muros.

Obra $n^{\circ} 4$ de Haring: Muro original pintado por Haring: Crack is Wack, mural en Harlem, Manhattan, New York, 1986.

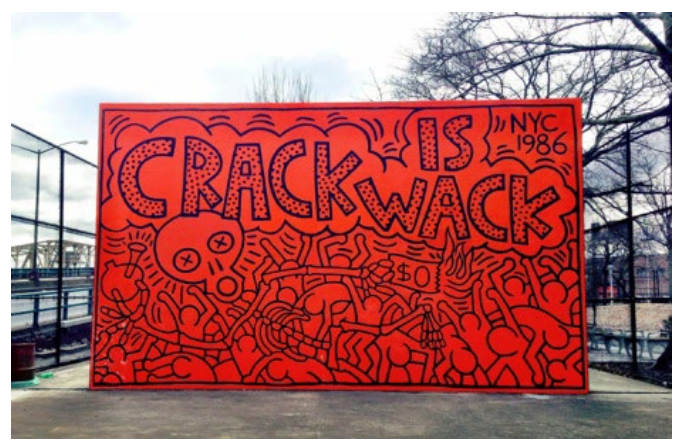

Fuente: <http://www.loveantoinette.com/the-crack-is-wack-playground-in-harlem/ img_2571/>.

Obra $^{\circ} 5$ de Haring: Muro pintado en el Grand Park, Chicago.

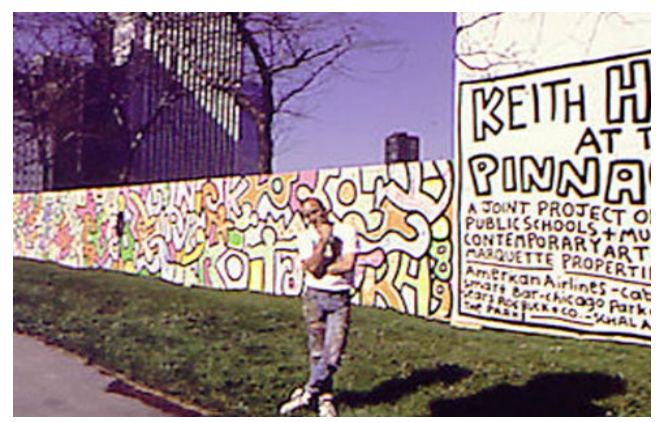

Fuente: $<$ http://jovem.ig.com.br/oscuecas/noticia/2010/08/04/mostra+sobre+keith+har ing+deixa+de+fora+lado+do+artista+que+inspirou+grafiteiros+9556063.html>.

En uno de los patios del colegio cercando la cancha de balonmano, se ubica un muro en el cual, vamos a reinterpretar la obra del autor, a modo creativo, es decir, serán los propios niños quienes decidan como colocarse y como pintar 
las siluetas. Para la realización de esta actividad, algunos niños se colocaron por parejas, los demás participarían en la segunda parte de la actividad. Un miembro de cada pareja se apoyaba de espaldas sobre el muro realizando algún movimiento corporal; el otro, iba realizando la figura del esquema corporal con una tiza, envolviendo así al compañero en una composición lineal realizada de un solo trazo (Imágenes de la 26 a 31).

Imagen 14 y 15 - Proceso del dibujo lineal de la propia silueta de los alumnos
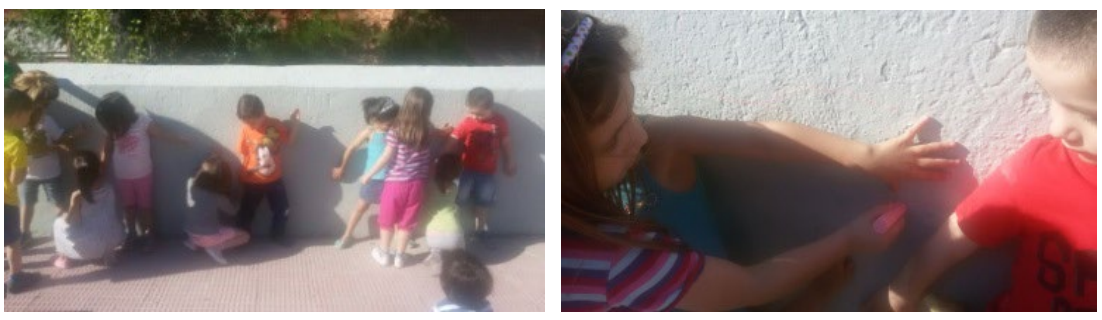

Posteriormente se pasó a pintar la figura de un mismo color, utilizando acrílicos especiales para fachadas. Cada pareja, con ayuda de otros compañeros, pintaba la suya.

Imagen 16 y 17 - Proceso de Pintar las siluetas con diferentes acrílicos. 27-5-2015
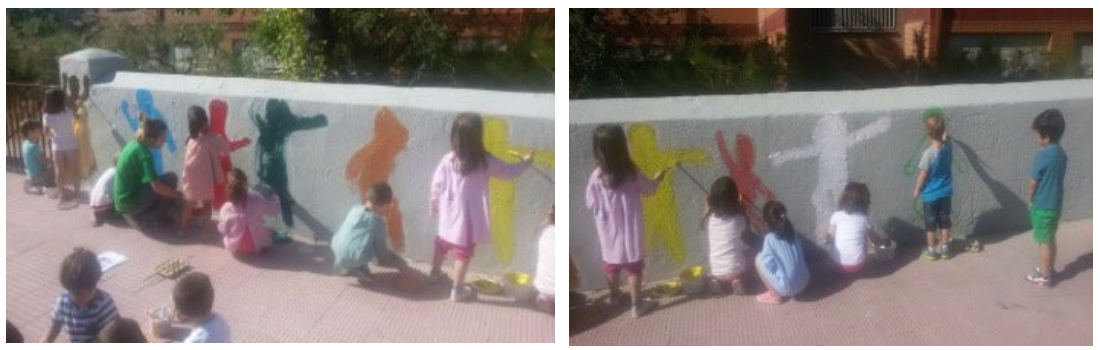

Una vez elaboradas todas las figuras, distinguimos el resultado final: 
Imagen 18 - Resultado final sobre el muro del centro. Día 28-5-2015

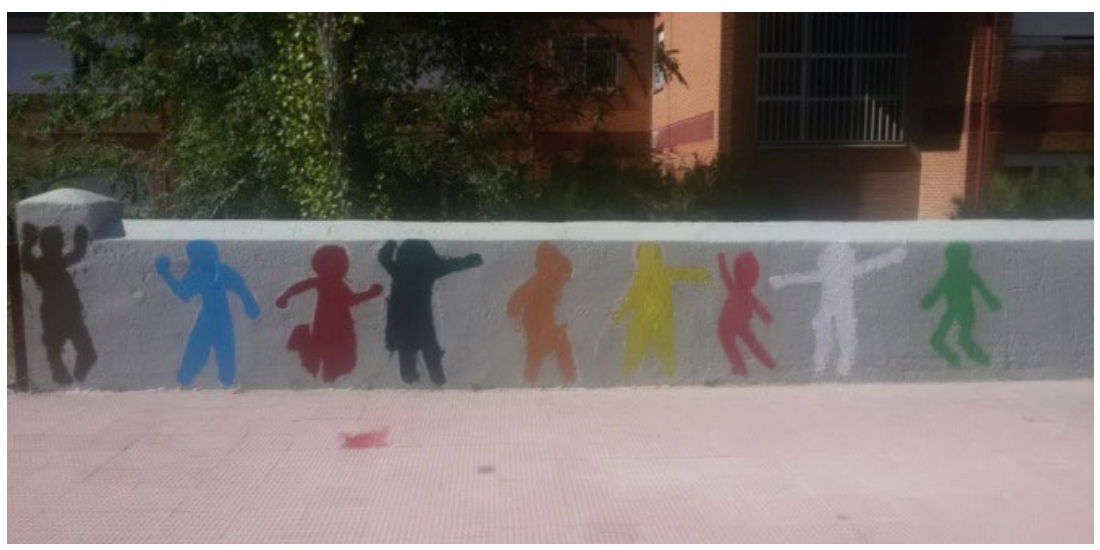

\section{Conclusiones}

A lo largo de esta propuesta didáctica, hemos corroborado como la creatividad influye positivamente en el proceso de enseñanza-aprendizaje, al mismo tiempo que implica una serie de capacidades relacionadas con el respeto, el trabajo en equipo y la observación de los procesos instruidos. La metodología constructivista facilita la interiorización de contenidos a nivel individual, por lo que, partir desde las necesidades significativas del alumno reconduce posibles carencias de los alumnos, generando así un cambio conceptual significativo.

Demostrar una nueva posibilidad de acercar el arte a la escuela, desde el estudio que ofrece un autor como Keith Haring, en cuanto a su concepción y a la forma de entender y comprender el arte, y, en cuanto a su interés por todo lo social y por lo urbanita, nos abre horizontes innovadores para aplicar en los currículos educativos. Simultáneamente, afrontar nuevos estándares de ejecución en el aula será el siguiente paso a lograr.

Llegamos a la conclusión de que nuestra sociedad avanza precipitadamente, obviando ciertos aprendizajes creativos de los propios ciudadanos. Como sujetos sociales e individuales que son los individuos, la escuela debe comprometerse a estimular aquellas nociones significativas que radiquen en el verdadero sentir del aprendizaje. 


\section{Agradecimientos}

Queremos agradecer la colaboración y las direcciones realizadas durante la didáctica a mi tutor de investigación Alfonso García de la Vega, al igual que en el proceso, guía del estudio y las correcciones orientadas en el presente escrito.

\section{Referencias}

BORTHWICK, G. Hacia una educación creativa. Madrid: Fundamentos, 1982.

CASAS, D. L. Keit Haring/Historia del Arte.Daniel Lasso Casas. Programa de diseño gráfico. Recuperado em: abr. 2015. Disponível em: <http://keithharingarte.blogspot.com. es/2013/01/biografia.html>. 2 de Enero de 2013.

CHICA DÍAZ, M. Las Tablas de doble entrada y su aplicación en el aula de Educación Infantil con niños de 4 y 5 años. Edma 0-6. Educación Matemática en la Infancia, 3(2), 37-52. 28 feb. 2015.

CHICA DÍAZ, M. et al. Aprendizaje Cooperativo-Aprendizaje compartido. Un proyecto conjunto de Arte en la Escuela. Aufop, U. d. Cantabria, Ed., p.1.048-1.057, 20-22 nov. 2014.

COLL, C. Significado y sentido en el aprendizaje escolar. Reflexiones en torno al concepto de aprendizaje significativo. Barcelona: Infancia y Aprendizaje; Universidad de Barcelona; Departamento de Psicología Evolutiva y de la Educación, 1988.

. Las comunidades de aprendizaje y el futuro de la Educación: El punto de vista del Forúm Universal de las Culturas. In: U. D. BARCELONA (Ed.). Simposio Internacional sobre Comunidades de Aprendizaje. Barcelona, 5-6 oct. 2001.

ESPAÑA. Ley Orgánica 8/2013, de 9 de diciembre, para la mejora de la calidad educativa. Lomce. Agencia Estatal. Boletín Oficial del Estado. 2013. Disponível em: <https://www. boe.es/boe/dias/2013/12/10/pdfs/BOE-A-2013-12886.pdf>.

GALlENO, A. P. El Programa. Ciudades Sostenibles. Más poder Local, 7, p. 10-12, oct. 2001.

GARDNER, H. Arte, Mente y Cerebro. Una aproximación cognitiva a la realidad. Argentina: Paidós, 1997.

LEY ORGÁNICA, 1. Ley Orgánica 15/1999, de 13 de diciembre, de Protección de Datos de Carácter Personal. 13 dic. 1999.

LOWEMFELD, V.;\& BRITAIN, W. L. Desarrollo de la capacidad creadora. Buenos Aires: Kapelusz, 1972. 
MADRID (Comunidad de Madrid). Decreto 17 del consejo de gobierno, por el que se desarrollan para la Comunidad de Madrid las enseñanzas de la Educación Infantil”. 17/2008, D. (2008 de 6 de marzo). Disponível em: <http://www.madrid.org/wleg/servlet/ Servidor?opcion $=$ VerHtml $\&$ nmnorma $=4922 \&$ cdestado $=\mathrm{P}>$.

MOREIRA, M. A.; ILEANA, M. G. Cambio Conceptual: Análisis crítico y propuestas a la luz de la teoría del Aprendizaje Significativo. Ciência \& Educação, 9(2), p. 301-315, 2003.

MOREIRA, M.; CABALLERO, M.; RODRÍGUEZ, M. Aprendizaje significativo: un concepto Subyacente. ENCUENTRO INTERNACIONAL SOBRE EL APRENDIZAJE SIGNIFICATIVO, Burgos. Actas... p. 19-44. 1977

PIAGET, J. Psicología del Niño. Madrid: Morata, 1973.

PULEO ROJAS, E. M. La Evolución del dibujo infantil. Una mirada desde el contexto sociocultural Merideño. Universidad de los Andes Mérida, Venezuela. Investigación Arbritada, vol. 16, núm. 53,p. 167-170. enero-abril, 2012.

RODRIGUEZ BELTRÁN, M. Educación y ciudad. La educación como elemento clave del desarrollo estratégico territorial. Forum Aragón, 6, p. 51-54, oct. 2012.

RODRÍGUEZ MONEO, M. Conocimiento previo y cambio conceptual. Madrid: Aique, 1999.

VIELMA V. E.; SALAS, M ${ }^{\mathrm{a}}$ L. Aportes de las teorías de Vygotsky, Piaget, Bandura y Bruner. Paralelismo en sus posiciones en relación con el desarrollo. Universidad de los Andes Mérida, Venezuela. Educere, vol. 3, núm. 9., p. 30-37. Junio, 2000

VYGOTSKY, L. S. Pensamiento y lenguaje. Trad. T. d. Rotger. Ediciones Fausto, 1955. Recuperado em Mayo 2015: Disponível em: http://educarteoax.com/blog/wp-content/ uploads/2016/01/Pensamiento-y-Lenguaje-Vigotsky.pdf.

Recibido en: 6/9/2016

Acepto en: 4/11/2016 